\title{
Substance Abuse and Stress Coping Strategy among Secondary School Students in Kano: Causes and Consequences
}

\author{
Shehu Aliyu Mukhtar \\ Department of Management Sciences Kano State College of Arts and Sciences P.M.B.3145, Kano-Nigeria
}

\begin{abstract}
Substance abuse and stress coping strategy has been widely examined, but still more is needed in the area. This paper aims at providing a propose framework that examined a direct relationship between substance abuse and stress coping strategy based on literature. The study will benefit stakeholders in Education, clinical psychologist, parent, students as well as government.

Keywords: Substance abuse, Stress coping strategy, students, Kano.
\end{abstract}

\section{Introduction}

The use of substance evolved from the awareness of its purpose and effect among secondary school students as a stress coping strategy. Proper and acceptable medication of substances has continued to improve the quality of human health and productive life. The proper use of substances has come to stay as one of the primary characteristics of human behavior in a wide variety of cultures. Substances/ drugs are as old as man, and that people are known to consume various drugs for various reasons, which includes: diagnosis, prevention, cure, maintenance of health and alleviation of pains and suffering (Aliyu, 2010). Thus, the continued and proper use of substances has remarkably distinguished mankind from other animals as it has often helped in the management of diseases.

Inspite of the usefulness of substances/drugs however, the problem of substance abuse has continued to have adverse effects in many communities. In view of this, Sambo (1991) asserted that the therapeutic use of drugs/substances is a great discovery by man to cure his ailment, yet substance abuse still remains one of the greatest hazards to man, because when a substance is abused it can render its victim useless. The most disturbing issue about substance abuse is that majority of people involved in this form of anti- social behavior are young people or teenagers who are expected to constitute the largest population of the nation manpower needed and equally the stakeholders of the nation's socio-economic and political development, and it was confirmed that many students use stimulant for relief from pain and other academic problems (Linhadt, 2001). Stress coping is used by students who normally engaged in substance abuse for them to create a kind of academic confidence and do away from any danger that might face them (Chikere\&Mayowa, 2011).

\section{Problem Statement}

The aim of the paper is to examine the conceptual relationship between substance abuse and stress coping strategy of students in Nigeria. The motivation was as a result of inconsistent findings in the previous studies between the two constructs. (Hyman, et.al, 2007; Hruskaet.al ,2012; Ehobhayi, 2013) found a significant positive relationship between the construct, Sun, et.al (2011) found a negative relationship.

\section{Literature Review}

\section{Substance Abuse}

It is important to note that substance and drug abuse are used interchangeably. Substance can be conceptualized from one of the following perspectives; legal, social, medical or pharmacology respectively.In law, a drug or a substance is referred to a chemical substance whose possession and use is against the law of the land. Thus, all narcotic's i.e. (cocaine, heroin, opinion, morphine) as well as non-medical use of amphetamine, codeine are considered drugs, Goode (2002).In sociology, drugs are collectively defined as substances prescribed by the medical profession which includes other drugs, the production and use of which are sanctioned by custom and law. They may always not be good for one's health, yet they are substances most people regard as beneficial, feel comfortable with or believe they can control (Erich, 1974).In pharmacology, a drug is any substance, other than food, that by its chemical and physical nature alters' structure of functions in living organism, Ray cited in Sambo(1991). This definition is similar to that of medical practices which regard drugs/substances as chemical used in medical therapy, Goode (2002).According to Garba (2003), a drug refers to any substance which by its chemical nature affects the structure and function of any living organism.

There is no one best accepted definition of substance/drug. However, all the definitions are useful for the various purposes they seek to achieve. Most people wish to think of illicit substance as drugs and legal 
substances as beverages e.g. (Liquor) or medicine. Someone who uses a chemical which the society consider illegal does not make him different from the person who uses a chemical which might have similar effect, but which the society have decided to keep legally available, Goode (2002).Ese and Rosemary (2012) defined a substance abuse as the arbitrary overdependence or misuse of one particular drug before any medical diagnosis from the qualified health practitioner.

\section{Causes of Substance Abuse}

Garba (2003) identified the following as the Major causes of substance abuse among students; these includes:

$\checkmark$ Experimentation/curiosity: Curiosity to experience the unknown facts about drugs does motivate students into drug use. Students like experimenting, the first experience may produce a state of arousal such as happiness and pleasure which in turn motivate them to continue.

$\checkmark$ Peer group influence: Peer pressure certainly plays a major role in starting many on drugs. Many young people's start to use drugs through the influence of their friends. Such people continue to use drug in order to get approval of others and to conform to the practice in their groups.

$\checkmark$ Lack of parental supervision at home: The family's hold on youths has become loose these days as a result of growing poverty and continuous guest for material gains. In Nigeria today, like in most developing countries life is a constant struggle to obtain even the basic essentials of life and many parents have no time to supervise their children during the day.

$\checkmark$ Personality problems due to socio-economic conditions: Students with personality problems arising from social conditions have been found to abuse drugs. The social and economic status of most Nigerians is below average. Poverty is wide spread, broken home and lack of job is on the increase, which finally resorts to substance abuse.

$\checkmark$ Availability of drugs: In many countries drugs have dropped in price as supplies have increase, which makes its relatively easy to get. If drugs are readily available in a community, students will have ease to access to them and will use and abuse them.

\section{Consequences of Drug/Substance Abuse}

Substance abuse brings about many adverse consequences, which affect the user, his family and the entire society. These adverse consequences can be categorized into three namely, physical, psychological and social.

$\checkmark$ Physical:Some of the physical effects includes damage to important organs like brain, liver, hypertension, chronic cough and above all some researches have shown that HIV infection associated with drug addiction is becoming significant socio pathological problem in Nigeria (Ahmad, 2002).

$\checkmark$ Psychological: Drug abuse leads to depression (state of being kin low spirit), anxiety, dementia (loss of memory), Hallucination (hearing or seeing an image when this is not real), moodiness and aggressiveness leading to the degeneration of the individual. Such individual with these characteristics is a waste of him/her self and the society at large.

$\checkmark$ Social: Socially the consequences of drug abuse to the nation are quite serious. The preponderance of youth addicts roaming the streets negatively affects the economy as a result of low productivity and shortage of efficient manpower. Public safety is subverted, as drug addiction is leading to incitement of both sexes to prostitution and criminal behavior. Attempt to establish a correlation between criminal violence and drug abuse had been made and there are claims that illicit drug users are higher in a population of criminals than non-drug users. Violence witnessed in various communities leading to bloodletting, raping (Floyds, et.al 2010), stealing has a link with drug abuse. The human and material resources lost during such violence have their effects on the stability of the nation Ige, (2000). A significant number of deaths from road accident have also been traced to the act of person's under the influence of drugs (NDLEA, 1996), cited in Aliyu (2010).

\section{Substance/Drug Classification}

Garba (2003) gives the following classification to what he refers to as principal drugs/substances. The drugs frequently and commonly used may be grouped into five major types:

$\checkmark$ The opiates like codeine, pathidine and morphine.

$\checkmark$ The central nervous system depressants; which include alcohol, sedative like valium, hypnotic and tranquilizers, like lexoten.

$\checkmark$ The central nervous system stimulants like the amphetamine and cocaine.

$\checkmark$ Cannabis sativa popularly known as marijuana or hashish.

$\checkmark$ Miscellaneous group which includes Zakarmil (Datura metal), inhalants like nitrous oxide, volatile solvents and household products like glues, spot removers and tube repair kit or solutions'. 


\section{Stress Coping Strategy}

Stress is difficult to define, despite the fact that everybody has it and talk about it. Stress means different things to different people and stressful situations are based on individual appraisal and interpretations, while some situations are inherently more stressful than others. Stress is the force or pressure caused by difficulties in life. It is also seen as hardship, constraining influence, pressure force, system of forces applied to a body. Mamman (2009), view it as a "circumstances that place physical or psychological demands on an individual and to the emotional reactions experienced in these situations". The term Stress described the psychological pressure that affect people. Mamman (2009), further described Stress as the invisible and silent killer. He maintains that the danger of unresolved Stress would be only a symptom of the real "disease" which is Stress. The treatment of an illness resulting from Stress may mean treatment of symptoms and unless the source is removed the symptom may persist or reoccur.

\section{Types of Stress Coping Strategies}

Iwuji (1990) identified two types of stress Coping Strategies as:

$\checkmark$ Direct Coping Strategy

This is acting in order to alter or change the environment that is causing the stress. The affected individuals normally experienced psychological distress, stigmatization and loneliness, whenever they try to free themselves from any worry, it will make them feel that they are still useful and relevant to the society.

$\checkmark \quad$ Indirect Coping Strategy

This is acting in order to minimize the significance of the stress. For instance, a person may engage in drinking, smoking, eating or any mis-used of substances. Any of these offers a temporary relief but does not solve the problems and if taken in excess or over a long period of time it causes additional stress for the body.

\section{Substance Abuse and Stress Coping Strategy}

There have been a number of studies conducted on substance abuse and stress coping strategy of students in various institutions of learning. Abianwu (2005) confirmed that cannabis is by far the most commonly used illicit drug with usage of $4 \%$ ofthe world population compared to $1 \%$ for all other drugs combined. Hyman, Paliwal and Sinha (2007), examined the relationship of personal history of childhood maltreatment and the perceived stress and stress coping style of recently abstinent and treatment engaged cocaine dependent adults. 50 men and 41 women were chosen as the sample, using both simple linear and multiple regression method for data analysis. The finding indicated that childhood maltreatment has significant association with greater perceived stress and stress coping style. Oshodi, Aina and Onajole (2010) also explainedin their study that marijuana is the most commonly used substance followed by tobacco. They further stressed that inthe United Kingdom, cross-sectional studies have shown that among students aged 15-16 years, at least $40 \%$ hadused illicit drugs, mainly cannabis, at some time during their lives. They also discoveredthat alcohol hypo-sedatives, tobacco and psycho stimulants were commonly abused substances with varyingfrequency rates found for both overall and specific substance use. They further noted that the lifetime prevalencedegrees of substance use among secondary and university students were found to vary between $1.5 \%$ for tobacco and $47 \%$ for psycho stimulants in Ilorin, Kwara State of Nigeria.Floyd, Hedden, Lawson, Salama, Moleka and Latimer (2010) examined the relationship between poly-substance use and sex trade, 343 black South African substance users recruited from Pretoria region between 2002-2006, using logistic regression analysis. The findings of the study shows that substance use was positively related to sex trade among person's using drug to cope with stress. Robberton, Xu and Stripling (2010), in their study using a sample of 305 African American found that stressor is positively related to drug use.On the other hand, the study of Sun, Stewart and Shum (2011), found a different result. Their investigation was whether University student's smoking behavior is related with higher level stress, it was found that stress did not have a direct effect on smoking behavior. Furthermore, Chikere and Mayowa (2011) found that in a number of school and college surveyed in Nigeria,alcohol use is the most common among students, with many drinking students having had their first drink in familysettings. They also discovered that the majority of students affected were initiated into the use of alcohol at a tenderage of 16-20 years.However, the study of Brewer and Lewis (2011), which examined the phycho-social features of incarcerated girls with substance use disorder using multivariate analysis of variance, provided similar result that girls with substance use disorder had higher rate of severity, they are more likely to have problems related to alcohol use, drug use and aggression. In contrast, Sun,Hruska and Delahanty (2012), examined posttraumatic stress disorder (PTSD) and alcohol related problems, using a sample of 144 undergraduates. Their findings established a significant positive relationship between PTSD and alcohol related problems. In a related study conducted by Ehobhayi (2013), identified the Phycho-social factors affecting adolescent alcohol abuse, using a purposive and Cluster sample selection. The outcome of the research indicated 
a significant association between peer group influence and adolescent alcohol use. The finding of Abdu-Raheem (2013), is in concord with the previous studies which indicated that drug abuse leads to poor student's performance in the two Nigerian States examined. Therefore, there is an inconsistent finding in the above studies, these calls for further research in the field.

\section{Research Framework}

The literature reviews indicate a direct relationship between substance abuseand stress coping strategy. Hence, the framework suggest that, stress coping strategy depend to a large extend on substance abuse.

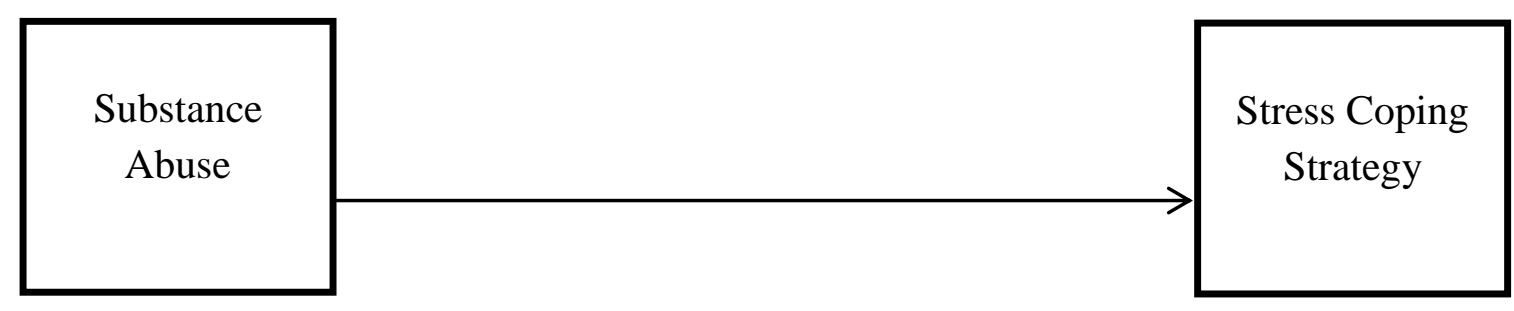

\section{Conclusion}

In this paper, effort has been made to provide a conceptual understanding of substance abuse as well as stress coping strategy of students. Issues related to causes, consequences, classification of substances were discussed. Stresscoping strategies as well as types of stress were also examined. The paper provided a framework which could serve as the reference model in the relationship between substance abuse and stress coping strategy. Future studies could examine the empiral relationship between the two constructs.

\section{References}

[1]. Abdu-Raheem, B.O. (2013). Sociological factors to Drug Abuse and the effects on Secondary School Students Academic Performance in Ekiti and Ondo States, Nigeria. Contemporary Issues in Education Research, 6(2), 233-240.

[2]. Abianwu, H. (2005). Emerging serious psychopathology associated with abuse of cannabis, Indian hemp, marijuana. Tropical Journal of Pharmaceutical Research, 4(1): 329-330.

[3]. Ahmad, M. (2002).Substance Abuse among university Students. Journal of Basic and Applied psychology, 3, 54-59.

[4]. Aliyu, M.S. (2010). Analysis of Stress coping patterns of Children with Substance Abuse Behaviors in Kano Municipal Education Zone.An unpublished M.Ed Dissertation, Bayero University, Kano.

[5]. Brewer, C.L., \& Lewis, A.C.R. (2011).Examining the Psychosocial functioning and characteristics of Incarcerated Girls with Substance Use Disorder.Child Adolescence social workJournal, 28, 175-187. DOI: 10.1007/s10560-011-0226-0.

[6]. Chikere, E.I.C., \&Mayowa, M.O. 2011. Prevalence and perceived health effect of alcohol use among maleundergraduate students in Owerri, South-East Nigeria: a descriptive cross-sectional study: BMC PublicHealth http://www.biomedcentral.com/14712458/11/118:1-6.

[7]. Ehobhayi, A.F. (2013). Psycho-social factors affecting adolescent alcohol abuse in Edo State, Nigeria. Achieves and Applied Science Research, 5(1), 88-92.

[8]. Erich, D. (1974). Personally Adjustment: the psychology of Everyday Life. U.S.A:Scholastic Book services.

[9]. Ese, A.G., \& Rosemary, O.O. (2012). Drug abuse and self-medication among youth: Causes and Consequences. Nigerian Journal of Education, Health and Technology research, 2(3), 169-176.

[10]. Floyd, L.J., Hedden, S., Lawson, A., Salama, C., Moleka, A.G., \& Latimer, W. (2010). The association between poly-substance use, coping, and sexual trade among Black South Africa substance users. Substance use and mis-use, 45,1971-1987.

[11]. Garba, A. (2003). Youth and Drug Abuse in Nigeria: Strategies for counseling, Management and control. Kano: Matasa Press

[12]. Goode, E. (2002). Drug and Youths: The challenge of today. New York. Scholastic Book Services.

[13]. Hyman, S.M., Paliwal, P., \&Sinha, R. (2007). Childhood maltreatment, perceive stress, and stress- related coping in recently abstinent cocaine dependent adults. Psychology and addictive behaviors, 21(2), 233-238.

[14]. Hruska, B., \&Delahanty, D.L. (2012). Application of the stressor vulnerability model to understanding posttraumatic stress Disorder (PTSD) and alcohol related problems in undergraduate population. Psychology and addictive behaviors, 26(4), 734-746.

[15]. Ige, S.G. (2000). A Motion on prohibition of sales of hemp to students in Pankshin Town.Pakistan: Al-Ilm press Ltd.

[16]. Iwuyi, V.B.C.(1990). Stress and modern living: How to cope excessive stress. Journal of research in counseling psychology, 2(1), $1-9$.

[17]. Linhardt, R.J. 2001.Drug in World Book Encyclopedia D, Vol. 5. Chicago World Book Inc. a Scott FetzerCompany.

[18]. Mamman, U.(2009). The effect of Stress and Self esteem on Academic Achievement of students in Tertiary Institution in Katsina State. An unpublished M.EdDissertation,Bayero University, Kano.

[19]. Oshodi, O.Y., Aina, O.F. \&Onajole, A.T. 2010. Substance use among secondary school students in anurban setting in Nigeria: prevalence and associated factors. African Journal of Psychiatry, 1(3): 52-57.

[20]. Robberton, A.A., Xu, X., \& Stripling, A. (2010). Adverse event and substance use among Female Adolscents Offenders: Effect of coping and family support. Substance use and Mis-use, 45, 451-472. DOI: 10.3109/10826080903452512.

[21]. Sambo, S. (1991).Drug Abuse among Secondary Schools in Kaduna metropolis.An unpublished M.Ed Dissertation, Ahmadu Bello University, Zaria.

[22]. Sun, J., Stewart, D., \& Shum, D. (2011). Mediating effect of coping, personal belief, and social support on the relationship among stress, depression, and smoking behavior in University students. Health Education, 111(2), 133-146.

[23]. West, L. \& Graham, C. (2005).A survey of substance prevention efforts at Virginia's colleges andUniversities.Journal of American College Health, 54(3), 185. 